Atos de Pesquisa em Educação - ISSN 1809-0354

Blumenau, v. 12, n.2, p.263- 285, mai./ago. 2017

DOI: http://dx.doi.org/10.7867/1809-0354.2017v12n2p263-285

\title{
SABER ELEMENTAR E A FORMAÇÃO DA RAZÃO COMUM EM CONDORCET: ENSINO DE MATEMÁTICA E EMANCIPAÇÃO
}

\section{THE ELEMENTARY KNOWLEDGE AND THE FORMATION OF COMMON REASON ACCORDING TO CONDORCET: MATHEMATICS TEACHING AND EMANCIPATION}

SILVA, Sidney Reinaldo sidney.silva@ifpr.edu.br IFPR- Instituto Federal do Paraná

\begin{abstract}
RESUMO Para Condorcet, a institucionalização do saber elementar se justifica como uma exigência ou condição da própria república na forma de democracia representativa. A república, segundo o Marquês, é o governo da razão comum e de uma constante submissão da lei às provas de sua validade. Mas, para avaliar e criticar as leis, são necessárias capacidades racionais que se desenvolvem e fortalecem por meio da instrução. Com a instrução pública, a razão estabelece os fundamentos de sua própria formação. Este texto apresenta o valor do saber elementar matemático na formação da referida "razão comum".
\end{abstract}

Palavras-chave: Condorcet. Ensino de Matemática. Razão Comum. Saber Elementar.

ABSTRACT According to Condorcet, elementary school knowledge is necessary for a republic as a representative democracy because the government of "common reason" is a continuous submission of the law to the evidence of its validity. But rational capacities that develop by means of public instruction are required to evaluate and criticize laws. With the public instruction, the common reason establishes the foundation of their own formation. This text presents the value of early years' elementary mathematics education for the formation of said "common reason".

Keywords: Condorcet. Elementary Knowledge. Common Reason. Mathematics Teaching.

\section{INTRODUÇÃO}

Questões em torno do que ensinar, para quem ensinar, para que ensinar e como ensinar estão ligadas à modernização social, cada povo que trilha esse caminho as problematiza e as resolve conforme as contradições que vivencia. 
Certas experiências nacionais reconfiguram as instituições, as ideias e os valores educacionais de tal modo que se tornam referências para outros povos. A Revolução Francesa foi um dos períodos mais marcantes nesse sentido. Conceitos como os de educação nacional e instrução pública carregam essa marca revolucionária do final do Século XVIII. Nesse sentido, as ideias do Marquês de Condorcet (1743-1794) sobre a educação não deixam de ser ainda uma referência crítica para se avaliar políticas educacionais.

Para Condorcet, a institucionalização do saber elementar se justifica como uma exigência ou condição da própria república, em sua versão da democracia representativa. Antes de ser o governo do amor às leis, como identificou Montesquieu, a república para o Marquês, é o governo da razão comum e de uma constante submissão da lei às provas de sua validade. Mas, para avaliar e criticar as leis, são necessárias capacidades racionais que se desenvolvem e fortalecem por meio da instrução. Frente a isso, Condorcet apresentou propostas de como formar a razão cidadã nas escolas públicas, compreendidas como o espaço onde a instrução deve ser universal e estar disponível a todos conforme exige a própria noção de democracia. Mas que razão é essa capaz de estabelecer os fundamentos de sua própria formação? Em que sentido o ensino de matemática é indispensável para a formação da razão?

Para responder a essas questões, é necessário, inicialmente, expor o significado da razão comum e da lei dada coletivamente, conforme Condorcet. Posteriormente, cabe mostrar a correlação entre a razão comum e o saber elementar, mostrando como este é constitutivo de uma democracia que se institui como esfera de exercício do direito ao voto tomado como expressão da soberania do povo. Finalmente, cabe mostrar a relação entre a aprendizagem do saber elementar matemático e a formação da autonomia do cidadão. Esta formação, como será visto, exige não apenas o domínio de conhecimentos básicos, mas também a aquisição da habilidade analítica ligada ao cálculo e à lógica como expressão da autoridade não arbitrária da razão. Essa aprendizagem é mostrada como uma ocasião para o entendimento de que quando se é submetido à razão não se deixa de ser livre. 
A presente exposição é feita basicamente a partir do estudo de dois textos de Condorcet: O Fragmento da décima época do Esboço de um quadro histórico dos progressos humanos e os Meios de aprender a contar seguramente e com facilidade. Outras obras foram retomadas para elucidar, indicar e aprofundar certos aspectos relacionados com a instrução pública, o ensino de matemática e a emancipação.

Os estudos sobre o saber elementar na perspectiva de Condorcet têm avançado muito recentemente. Destacam-se, inicialmente, as obras de Catherine Kintzler $(1994,2013)$ Charles Coutel $(1995,1996 a, 1996 b, 1996 c$, 1998, 1999), autores que retomaram, as investigações sobre a educação em Condorcet, lançando novas luzes sobre questões antigas e descobrindo novos temas e problemas. Destacam-se seus textos sobre a instrução pública, república e cidadania, as dimensões jurídicas, epistemológicas e pedagógicas da escola e do saber elementar na obra do Marquês. Mais recentemente, despontaram as investigações de Alan Trouvé (2007, 2008, 2010a, 2010b), que focou o "elementar", estudou suas origens, esquecimentos e retomadas. Este autor destacou a crise do elementar devido à superação do paradigma filosófico e epistemológico que o sustentou desde o início de sua discussão, mostrando, contudo, possibilidades de atualizá-lo, incorporando a ele novas perspectivas, tais como a da complexidade, e novas considerações, como as éticas e as culturais. É relevante também a forma como este autor retoma os estudos do saber elementar em Condorcet, especialmente quando o compara com autores como Pestalozzi.

No Brasil, destacam-se os estudos de história da educação matemática de Maria L. Gomes (2002, 2003, 2009), que, em sua tese de doutorado, pesquisou as ideias de Condorcet, Condillac, D'Alembert e Diderot sobre a educação matemática, produzindo também analises específicas sobre o texto pedagógico de Condorcet intitulado Meios de aprender a contar seguramente e com facilidade. Os estudos de história da educação matemática e do elementar de Wagner Rodrigues Valente $(2012,2015)$ têm contribuído para mostrar novos aspectos da recepção da obra de Condorcet no Brasil e, sobretudo, para discutir a noção do elementar na perspectiva da formação do cidadão. 
É a partir das contribuições das pesquisas acima elencadas que procurei mostrar a relação entre democracia, autonomia, saber elementar e o ensino de matemática em parte da obra de Condorcet.

\section{A RAZÃO COMUM}

Emancipar, para Condorcet, significa sair da menoridade cognitiva, deixar de ser tutelado pelo erro (preconceitos, fanatismos, superstição, charlatanismos e sofismas) e não se submeter a uma razão estranha e autoritária (formas tecnocráticas de poder: despotismos esclarecidos). A libertação (liberation) da mente (individual) e a libertação do cidadão são processos complementares (WILLIAMS, 2007). Essa emancipação se faz com o uso da razão, da capacidade de submeter tudo à análise e só decidir depois de examinar o "motivo de crer" na verdade de uma proposição tanto na perspectiva individual quanto no prisma coletivo. Por isso, a emancipação coletiva exige a formação pública da razão comum.

O programa de instrução pública condorcetiano quer estabelecer para todo cidadão o que Bacon teria proposto para um indivíduo. Trata-se de ensinar a suspender as opiniões recebidas, refazer a própria inteligência, analisar e recompor todas as ideias que se tem sobre as coisas relevantes para a vida. Isso exige aprender a recusar tudo o que não se justifica racionalmente (CONDORCET, 1968, VI, 581). Condorcet trata dessa questão no texto intitulado Fragmento da décima Época, que se apresenta como uma janela ou desdobramento do Esboço de um quadro histórico dos progressos do espírito humano. A sua intenção nesse texto foi a de expor como a "arte social" pode conciliar a razão individual com a razão comum e constituir a moral de um povo.

A proposta condorcetiana de formação do povo pressupõe prioridade do racional sobre o volitivo. No texto Da natureza dos poderes numa nação livre, o autor estabeleceu a seguinte relação entre razão e vontade: 
estabelecidas em conformidade com a opinião majoritária; a vontade geral exige que tal aplicação da lei seja executada. (CONDORCET, 1968, II, p. 596. Tradução do autor)

Ao fundar a soberania sobre a razão da coletividade e não na sua mera vontade, Condorcet quer dizer que o poder da maioria sobre a minoria não deve ser arbitrário (CONDORCET, 1968, p. 590). A instrução pública elabora o trabalho prévio de formação da razão e da vontade do povo. Coutel (1996) destaca que os saberes elementares constituem-se no "alfabeto" da razão comum, sem o que a vontade geral não poderia ser esclarecida.

O problema da expressão da razão comum diz respeito à passagem do juízo individual para o juízo coletivo, o que recoloca Condorcet na rota de Rousseau (GROFMAN, FELD, 1988; ESTLUND, WALDRON, GROFMAN, FELD, 1989). Assim entram em questão as regras técnicas do sistema de eleição e as condições exigidas dos votantes para que isso possa de fato ocorrer. A decisão conforme a verdade tem aspectos formais e de conteúdo. A forma diz respeito à correção dos procedimentos institucionais e técnicos de apuração da razão comum, o conteúdo refere-se à instrução pública, responsável pela qualificação do juízo individual. Os vereditos da razão comum dependem da justeza das instituições e da vontade (esclarecida) dos indivíduos de tomarem decisões conforme a verdade. Um conhecimento básico é necessário, sem o qual o erro torna-se mais frequente do que a decisão de acordo com a verdade. Sem isso, um coletivo assim como um indivíduo, não poderia identificar o que ele quer, nem o que ele considera razoável e justo.

No que se refere à formação da razão, o saber elementar apresenta-se como constitutivo para garantia da liberdade (agir conforme a própria vontade, dar seu consentimento, o que se revela no ato de votar) e garantir as condições de veracidade (que o resultado do voto não seja contrário ao conhecimento disponível num determinado momento do "progresso" da humanidade). Há, portanto, um conhecimento necessário para o exercício da razão sobre objetos de interesses diversos, sem o qual o erro não pode ser evitado. O erro é relacional e epistêmico: ele é mecanismo de dominação ligado à produção social da inabilidade cognitiva individual frente à realidade. Trata-se de "preservar [os indivíduos] dos erros nos quais a esperteza de outros homens ou 
mesmo a impressão dos próprios objetos poderiam os arrastar" (CONDORCET, 1968, VI, p. 519). O erro expressa-se em decisões que não avaliam o "motivo de crer" que as sustentam, ou seja, no agir sem bem ponderar, cedendo às impressões enganosas sobre o que atente ou não ao próprio interesse, mesmo tendo uma percepção errada deste. A formação atenta do motivo de crer exige cuidado didático.

A lógica e o cálculo são expedientes a serem dominados ao menos "minimamente" para garantir a autonomia. Os saberes elementares são aqueles capazes de tornar tais expedientes acessíveis aos indivíduos. Segundo o autor, tais elementos de lógica podem ser colocados à altura de quase todas inteligências (presque tous les esprits): "pois é suficiente compreender neles as consequências práticas e sensíveis, que resultam da análise rigorosa dos motivos de crer e dos métodos mais exatos de os avaliar" (CONDORCET, 1968, VI, p. 568. Tradução do autor). No Fragmento da décima época, relativo ao período em que para Condorcet a desigualdade de fato entre os seres humanos seria eliminada pela arte social, discorre-se sobre os instrumentos dessa forma de controle dos homens sobre si mesmo e sobre o seu meio, o que teria sido conquistado como o mais avançado estágio de sua liberdade.

Segundo o referido texto, numa sociedade livre, o saber elementar está a serviço da universalização do uso independente de uma razão esclarecida entre um povo (usage indépendent d'une raison éclairée). Isso significa instruir para que todos possam formar ideias precisas; ter justeza em seus juízos, raciocinar com exatidão (CONDORCET, p. 574). Trata-se de formar uma base flexível, isto é, capaz de ser continuamente aperfeiçoável para estar sempre à altura das novas exigências trazidas pelos "progressos" das ciências e das técnicas. Está em jogo o domínio da arte de aprender por si mesmo e ter acesso a uma constante formação. Essa base é descrita como conjunto de regras de pensamento que possam

Conduzir o desenvolvimento de seu espírito (do cidadão) de maneira a formar sua inteligência com precisão, conservar com nitidez essas noções primeiras destinadas a serem a base de suas opiniões e de seus princípios, de modo que eles possam adquirir os conhecimentos necessários para examinar e decidir as questões que suas 


\begin{abstract}
necessidades, interesses e os acontecimentos da vida comum podem Ihes exigir soluções para resolverem, que as regras necessárias para dirigir seus juízos guiando-os em seus raciocínios lhes sejam familiares, e que, enfim, um exercício habitual dê as suas faculdades a força, a flexibilidade, a fineza e a facilidade necessária para procurar sem esforço e reconhecer com segurança as verdades úteis a sua felicidade (CONDORCET,1968, VI, p. 574-5. Tradução do autor)
\end{abstract}

Saber definir termos, formar proposições e raciocinar torna-se o eixo da instrução pública. A formação elementar é a base para a aprendizagem do cálculo das probabilidades como uma forma de orientar-se no mundo (CONDORCET, 1968, VI, p 560). A razão em política não lida com certezas, mas com uma verdade aproximável.

\title{
3 A FORMAÇÃO DA RAZÃO COMUM
}

As regras comuns devem decorrer de procedimentos que asseguram o máximo possível (garantia de uma probabilidade tão alta quanto possível) que o erro não prevalecerá nas decisões dentro das condições especificadas. Para Condorcet isso é uma exigência que cidadãos livres e iguais não podem abrir mão. Sua concepção de democracia é epistêmica, o que está em jogo nas deliberações coletivas é a verdade de proposições votadas.

Ao fazer parte do corpo político, por meio do direito ao voto, o indivíduo se expõe às consequências das decisões coletivas com as quais tem que consentir. Contudo ele precisa ser protegido desse mesmo corpo do qual é integrante para que sua autonomia não seja dissolvida e seus direitos naturais não sejam violados, evitando perder a sua singularidade e mesmo a supressão da racionalidade pela mistificação da vontade geral e da lei que é sua expressão. Não há "sacrifício" a ser feito, pois nada é sagrado em política para Condorcet:

Quando eu submeto minha vontade a uma lei que não aprovo, não ajo verdadeiramente contra minha razão, mas a obedeço; porque ela me diz que em tal ação, não é minha razão particular que deve me guiar, mas uma regra comum a todos, e a qual todos devem estar submissos. Assim, a lei não exige realmente nenhum sacrifício da razão ou da liberdade dos que não a aprovam. (1968, IX, p. 4. Tradução do autor) 
Os riscos ao qual o indivíduo-cidadão está exposto referem-se tanto à forma quanto ao conteúdo da composição do corpo político. A questão que surge é, portanto, a de como conciliar um governo da razão com a soberania popular.

A vontade só é aceitável como geral se for racional e livre. Um homem livre se submete apenas à verdade produzida por um procedimento racional. Ao exigir isso, Condorcet pretendeu submeter as eleições ao rigor do cálculo, o que o levou a deparar-se com paradoxos que formalmente poderiam inviabilizar a democracia. Contudo, via nisso uma exigência da própria democracia, para a qual é "imprescindível fundamentar e legitimar os meios de se aferir a opinião ou a vontade da coletividade" (EPISTEIN, 1997, p. 274). Rousseau, no Contrato Social, mostrou que o corpo político (a assembleia, a reunião de todos os cidadãos) é o único soberano, isto é, o único cuja decisão expressa a vontade geral. A unanimidade resulta do aval da vontade geral. Contudo, afirma Epistein, devido à raridade desse fenômeno, "é necessário confiar na vontade da maioria, que, sem ser necessariamente a de todos, é estabelecida segundo aquela vontade". (EPISTEIN, 1997, p. 274).

Condorcet retomou as questões da apuração da vontade geral do Contrato Social de Rousseau. Para ele, na democracia, o ponto principal refere-se a uma exigência capaz de evitar que a vontade geral desande em uma vontade despótica. Em se tratando de um procedimento racional, a decisão coletiva precisa de mecanismos capazes de dar certa garantia de que o erro será evitado. "As decisões devem, ao máximo possível, se premunirem contra o erro" (COUTEL, KINTZER, 1994, p. 22). Trata-se, como já foi mencionado, de uma democracia epistêmica, comprometida com a apuração de uma verdade. A razão legisladora precisa revisar seus escrutínios sempre que os avanços do conhecimento apontam para seus equívocos. A verdade política nunca é definitiva.

Quando se trata da cidadania, a liberdade e a igualdade são exigências incontornáveis. Para o Marquês, um indivíduo livre só obedece à razão. Contudo, quando está em jogo decidir sobre uma regra comum a todos não é sua razão que conta, mas a razão comum. Retoma-se o princípio da moral 
provisória cartesiana de que a virtude consiste em seguir o melhor raciocínio possível acessível ao entendimento no momento da decisão. O que vale para o indivíduo vale também para a coletividade.

Frente às exigências da democracia epistêmica, nem toda forma de ensino é válida. A garantia da liberdade e da igualdade, tal como as entendia Condorcet, está vinculada ao saber elementar. Contudo, qual a melhor forma de democratizar, de estender seu acesso a todos? Essa questão abre o debate em torno da incompatibilidade entre educação e instrução na escola pública, querela que se estabeleceu a partir das ideias de Condorcet.

\section{EDUCAÇÃO, INSTRUÇÃO E A RAZÃO COMUM}

Pode-se exigir uma educação elementar comum para todo cidadão? Sendo o caso, o que deveria ser ensinado? Seria isso um despotismo ou uma forma de combater o despotismo?

Conforme Condorcet, uma educação elementar racional é uma contradição em termos. Uma vez que seus métodos, objetos e objetivos não se baseiam em princípios epistemológicos e jurídicos capazes de garantir a liberdade, ou seja, de preparar para o uso da razão. Nesse sentido, o autor opõe a instrução à educação. A instrução, por seu lado, se justifica porque mobiliza saberes elementares emancipadores, isto é, ela é correlata da verdade (que decorre do uso da razão) e da garantia dos direitos naturais, reconhecidos pela própria razão como inalienáveis (CONDORCET,1968, XII). A diferença entre educação e instrução é de caráter metodológico, epistemológico, jurídico.

Uma educação quando imposta ou como a única disponível para todos cidadãos é despótica, sobretudo quando ela faz apelo ao entusiasmo, as formas catequéticas de doutrinação a serviço de mistificações políticas. A concepção de laicidade do autor não aceita nenhuma forma de religião cívica ou de culto às leis e instituições estabelecidas, o que poderia ser facilmente feito em nome de uma educação nacional.

Por seu lado, uma instrução pública é considerada necessária para combater o despotismo, seja este de um indivíduo, de alguns ou de uma 
grande maioria. Há, portanto uma imensa diferença entre educar e instruir como projeto nacional/público da formação cidadã. Existem entre elas incompatibilidades conceituais e políticas. No entender de Coutel (1995), a instrução revela a primazia da razão e a educação diz mais respeito à formação da vontade geral ${ }^{1}$. Mas de qualquer forma, instruir é esclarecer a vontade, tal como o mostra a teoria do motivo de crer.

A educação, no contexto da crítica condorcetiana, forma disposições para crer sem analisar os motivos e as razões. Ela também diz respeito ao privado, aos valores que dividem os cidadãos de acordo com suas crenças particulares (religião) e afiliações a grupos e interesses específicos, como os dos pais de alunos. Os próprios métodos da educação são despóticos, pois o conhecimento é transmitido de forma mecânica, maquinal, entusiástica, sem que o estudante possa chegar por si só a compreensão daquilo que aprende com o auxílio dos mestres. A educação prepara para crer sem analisar. A razão, tal como Condorcet a concebeu, não é seu baluarte.

A educação necessariamente não se compromete com uma formação racional, podendo mobilizar sentimentos e apegos não abertos à investigação de sua gênese e dos reais motivos de adesão a eles. Por não se dirigir, nem respeitar as exigências da razão, princípio da autonomia humana, a educação é um instrumento de fácil uso pelos despotismos. Sendo assim, ela não é uma forma adequada de enfrentar a desigualdade baseada no acesso ou não acesso ao conhecimento, não podendo combater, o que para Condorcet era o modo de dominação social mais elevado, a divisão entre os que ensinam e os que creem, entre os que sabem e não sabem, entre os que monopolizam o conhecimento e os que são mantidos alijados dele.

A instrução, por seu lado, permite combater formas de dominação e de sujeição a uma vontade arbitraria, permitindo a um povo republicano seguir apenas leis que encarecidamente consente. Esse consentimento exige juízo baseado em conhecimento e fundado em motivos racionais. A autonomia de

\footnotetext{
1 "Condorcet ne parvient pas à penser une "élémentarisation" de la prise de conscience éthique et politique chez les futurs citoyens; comment en effet enseigner ce qui est l'objet d'une prise de conscience globale ? La volonté générale semble devoir être l'objet d'un " amour » et non d'une démonstration. Condorcet n'envisage l'affirmation de la volonté générale que comme un effet immédiat de la combinaison aléatoire des savoirs élémentaires (la raison commune éclairant la volonté générale et non l'inverse)". (COUTEL, 1996, p. 337)
} 


\title{
DOI: http://dx.doi.org/10.7867/1809-0354.2017v12n2p263-285
}

um povo tem uma dimensão epistêmica irredutível: ela diz respeito à verdade de uma decisão coletiva. Nem tudo pode ser decido por todos, mas tudo o que é decidido tem que ser justificado para todos. Isso, na perspectiva democrática de Condorcet, é algo com o qual a soberania popular tem que aprender a lidar para não se enganar. A soberania precisa ser escalonada sem, contudo, perder ou fragmentar sua colegialidade.

\begin{abstract}
Mais uma constituição verdadeiramente livre, segundo a qual todos as "classes" da sociedade possuem os mesmos direitos, não pode subsistir se a ignorância de uma parte dos cidadãos não lhes permite conhecer a natureza e os limites dos mesmos, obriga-os a pronunciar sobre o que eles não conhecem, a escolher quando não podem julgar. Uma tal constituição destruiria a si mesma depois de algumas tempestades, e degenerariam em uma dessas formas de governo que não podem conservar a paz no meio de um povo ignorante $\mathrm{e}$ corrompido. (CONDORCET,1994a, p. 81. Tradução do autor).
\end{abstract}

Frente a isso, de nada adiantaria libertar a instrução de toda forma de autoridade (costume, religiosa, governo, charlatães) se não a livrar da opinião comum entravada: "cabe a ela avançá-la, corrigi-la e formá-la e não a seguir e obedecer" (CONDORCET, 1994a, p. 97). A razão coletiva se constitui nesse movimento.

A desigualdade de conhecimentos não produz necessariamente dominação quando o saber elementar é partilhado. O nivelamento ou abolição das diferenças de saber seria catastrófico para uma sociedade. Sobre isso, destacam Coutel e Kintzler (1994, p. 313, nota 14), que "quem se submete porque reconhece a superioridade de conhecimento ou de talento de outro não se submete senão sua própria razão" Tal como se reconhece a necessidade de seguir a razão comum quando está em jogo a produção de uma lei, assim também é racional seguir um parecer de alguém capacitado para isso quando interesses pessoais estão em jogo. Isso justifica a autoridade do instituidor, do professor que ensina o saber elementar.

Numa relação emancipadora de ensino aprendizagem, a razão não se perde quando se confia na autoridade do professor, desde quem sabe mais não subordine quem sabe menos ou o mantenha numa dependência crédula. Cabe aprender a examinar os próprios motivos que levam alguém a admitir como válida uma autoridade. Para Condorcet, a autoridade do professor se 
legitima na medida em que ele exerce de forma partilhada a razão com o aluno. O professor da escola primária também deve partilhar da razão dos sábios, o que ocorre, por exemplo, quando se orienta conforme um manual para os instituidores. Isso não é incompatível com a ideia de que o ensino dos saberes elementares baseia-se numa pedagogia dialógica, que recusa toda forma arbitraria ou injustificada de ensinar, que prepara para se desconfiar dos próprios conhecimentos adquiridos, submetendo-os a constantes provas.

\section{O AGENCIAMENTO DO SABER ELEMENTAR}

O saber elementar resulta do estabelecimento de uma proporção "entre o que é minimamente necessário para o agenciamento da instrução e a extensão real dos conhecimentos em um momento dado" (COUTEL, KINTZLER, 1994, p. 26). Trata-se de um equilíbrio máximo/mínimo. A questão não é de ensinar tudo a todos, mas de mobilizar, na medida do possível o conhecimento disponível para ensinar "a julgar remontando aos princípios do julgamento" (COUTEL, KINTZLER, 1994, p. 25). O saber acumulado pela humanidade torna-se um patrimônio a serviço do cidadão instruído (CONDORCET, 1998, p. 209).

A instrução trabalha com a desproporção entre o que já se conhece e o que se tem desejo e necessidade de conhecer. Frente a isso, cabe combinar os saberes elementares de maneira que possam servir de base a estudos mais prolongados e que nada do tempo usado para acompanhá-los seja perdido para o resto da instrução (CONDORCET, 1994a). Instruir é preparar para desenvolver a capacidade de adquirir conhecimentos novos e enfrentar as mudanças de situação, o que dá ao conhecimento um caráter flexível e aberto.

Ainda que o conhecimento universal e o patrimônio acumulado pelo espírito humano sejam as referências para a instrução elementar, esta não pode ser oferecida de modo descontextualizado, sem levar em conta os interesses dos alunos e as necessidades particulares de cada região. Condorcet (1994b) propõe que os livros didáticos levem isso em conta e que 
eles sejam produzidos de modo diferenciado conforme o destino que terão, respeitando demandas dos alunos do campo e da cidade.

Cabe à lei proteger a instrução elementar dos limites dados pelo particularismo, utilitarismo, interesses imediatos. Coutel e Kinzler (1994, p. 27) apontam essas exigências como "jurídicas" e não "sociais", pois fazem apelo ao universal do cidadão. Assim o Estado, protegendo a instrução através da lei, pode torná-la independente do poder, isto é, resguardá-la dos grupos de pressão, mesmo os ligados ao governo. Eis as exigências para isso, tal como as elencaram Coutel e Kintzler (1994):

\footnotetext{
1- Colocar os saberes e seus agentes na medida do possível livres do poder (político, religioso econômico). Professores do secundário e do superior, escolhidos conforme suas competências epistemológicas, seriam protegidos por lei. (p. 28)

2- Proteger os alunos dos professores e de possíveis arbítrios: exigir o método baseado na razão e na experiência. (p. 29) Isso para resguardar a instrução do entusiasmo, do sentimentalismo e de mistificações.

3- Manter apenas a autoridade da razão e da experiência raciocinada. Proteger a educação contra todo monopólio, mesmo do poder público. Estimular a comparação entre escolas públicas e privadas como forma de garantir a qualidade do ensino (p. 31).
}

São esses princípios que orientam o agenciamento do saber elementar. Além de não se limitar ao dado, aos fatos, pronunciando-se em termos de direito, o agenciamento do saber escolar obedece também a uma razão tabular. Os quadros são exposições rigorosas dos conhecimentos disponíveis num determinado momento e numa determinada área do saber. Trata-se da exposição de elementos das ciências que permitem a combinação de novos conhecimentos. Esses quadros referem-se a diversas ordens do conhecimento. Retomando ainda Kintzler e Coutel (1994a) tem-se o seguinte esquema: Saber ato: a constituição histórica do conhecimento, a ordem das descobertas; Saber em exposição em tratados: reconstrução da ordem de inteligibilidade; Saber escolar - apresentado conforme a ordem de aprendizagem.

A combinação básica se dá com a prioridade da ordem inteligível e o começo na ordem de aprendizagem. Daí decorre a diferença entre os elementos escolares e os científicos, o que se deve levar em conta no processo de transposição didática (COUTEL, 1995). Os elementos escolares, 
não são idênticos para todas as idades e níveis dos alunos, mas são derivados de elementos (formais) comuns, aqueles que são aceitos como condição da verdade.

Cabe ainda lembrar que a "elementarização do saber escolar torna efetiva uma articulação entre a razão comum (que concebe a lei) e a vontade geral (que executa a lei)" (COUTEL, 1995, p. 18. Tradução do autor). Frente a isso, o ensino de matemática tem uma importância fundamental na instrução pública, pois esta ciência é indispensável para garantir condições formais para a apuração da razão comum e para formar um cidadão capaz de reconhecer a autoridade da razão não somente no âmbito jurídico-político, mas também no epistemológico-pedagógico. Os elementos do saber precisam ser ensinados como o "início" de um encadeamento, ou seja, como capaz de levar a conhecimentos mais elevados e amplos. Kintzler (1994) vê nisso uma recusa da aprendizagem com fins meramente pragmáticos que parcelam o saber conforme necessidades pontuais.

\section{ENSINO ELEMENTAR E AUTONOMIA NOS MEIOS DE APRENDER A CONTAR COM SEGURANÇA E FACILIDADE}

A epistemologia de Condorcet tornou muito mais complexa do que a combinação entre cartesianismo e a filosofia de John Locke, tal como foi a tendência marcante na França no fim do século XVIII. Isso se deve mais a um recuo do que a um avanço na história da filosofia. Bernard Bru (1994) destaca o diferencial condorcetiano como uma forma de incorporar o platonismo na filosofia probabilista, tornando-se, assim, um "idealista estatístico" ao mesmo tempo que "frequencialista subjetivista". (Bernard Bru,1994, p. 13).

Em seu texto didático Meios para aprender a contar seguramente e com facilidade $^{2}$, Condorcet recuou em relação ao movimento de sua própria

\footnotetext{
${ }^{2}$ Texto escrito em 1794. "Esse tratado inacabado devido à morte de seu autor, quando fugia da perseguição do governo do Terror durante a Revolução Francesa, é um manual didático redigido com a intenção de participar de um concurso promovido por esse mesmo governo para selecionar os livros elementares a serem usados na instrução pública. A realização do concurso resultava de um aspecto característico da política educacional da França revolucionária - a composição de livros didáticos destinados a todo o país como praticamente o único meio de efetuar reformas no ensino" (GOMES, 2002, p. 5).
} 
concepção de conhecimento, sobretudo quando associou lógica e cálculo à maneira de Condillac (GOMES, 2003).

Um aspecto que repercutiu no texto de Condorcet sobre o ensino dos elementos de matemática diz respeito ao modo como Condillac retoma as três operações intelectuais consideradas básicas: a formação de ideias, o juízo e o raciocínio. Esses são elementos lógicos constitutivos da máquina do conhecimento racional a ser desmontada e montada pela análise. Nesse sentido, Condillac (1798) leva a análise ao extremo, quando estuda a arte de calcular.

Para Condorcet (1994b), ao instruir, a matemática apresenta-se como fator civilizatório, permitindo aprendizagens práticas de controle racional da imaginação. Seguindo o modo de representação dos objetos na matemática, o professor não abusaria da imaginação do aluno, ainda que isso seja eficaz para se ensinar ${ }^{3}$. Condena-se a imaginação por ele estar associada ao entusiasmo e a formas de arrebatamento que cancelam a partilha da razão entre professor e aluno. Contra o seu mau uso, cabe seguir o exemplo dos geômetras e dos algebristas, levando em conta como eles lidam rigorosamente com a imaginação.

A matemática diz muito a respeito do que Condorcet entende por uma sociedade efetivamente livre, que garante uma instrução elementar comum como meio de tornar real a igualdade de direitos e como base para garantir a soberania popular. Para se resguardar a igualdade de fato, cada cidadão deve ter acesso a uma instrução que o torne autônomo, não dependente de outros, no relativo ao saber elementar capaz de orientá-lo no mundo em que vive, de capacitá-lo para votar conforme à verdade na maioria das vezes em que exercer o direito de sufrágio, sem o que ele não pode garantir seus interesses razoáveis, ou seja, esclarecidos. O saber elementar, do qual os princípios da matemática são constitutivos, tornam o indivíduo num cidadão de fato, isto é, participante competente da razão comum.

\footnotetext{
3 "Um exame frio e severo, no qual apenas a razão seja ouvida, deve preceder o momento do entusiasmo. (...) A imaginação é a faculdade de captar uma sequência mais ou menos extensa de ideias com formas sensíveis (...). O geômetra, em suas meditações, vê relações abstratas representadas por figuras; e o algebrista as vê expressas em formas escritas" (CONDORCET, 1994b, nota 1, p. 145. Tradução do autor)
} 
Em sua configuração, o saber elementar combina forma - capacidades lógicas e de cálculo- e conteúdo - conhecimentos suficientemente atualizados, um mínimo estratégico do máximo acumulado como patrimônio da humanidade. A autonomia garantida pelo saber elementar também é relativa à maneira como se aprende, isto é, sem autoritarismo e credulidade. No ensino emancipador, não tutelado, nada ou nenhum passo é apresentado como arbitrário ou injustificado ao aluno. A autoridade pedagógica se legitima quando ela cria um espaço de partilha da razão entre o aluno e o professor (instituteur). Não seria aceitável conduzir o aluno cega e mecanicamente ao conhecimento.

O modo de conceber o poder emancipador da aritmética ilustra a força do saber elementar. Segundo Condorcet (1994a, p. 62. Tradução do autor), "quem ignora a Aritmética depende realmente do homem mais instruído, ao qual é obrigado a recorrer incessantemente". Isso afeta a igualdade entre os indivíduos. $\mathrm{O}$ desconhecimento da aritmética torna alguém não igual "àqueles a quem a educação deu esses conhecimentos" (CONDORCET, 1994a, 62. Tradução do autor). Com isso a extensão do direito à autonomia é reduzida, pois esta não depende apenas da vontade individual, mas exige condições que somente a coletividade pode garantir a cada um, no caso a instrução pública. O saber elementar é uma forma de partilha da razão entre pessoas com níveis de conhecimentos diversos, de modo a garantir a autonomia de quem sabe menos.

\footnotetext{
Mas o homem que sabe as regras da Aritmética, necessárias para os usos da vida, não está na dependência do sábio, que possui no mais alto grau o gênio das ciências matemáticas, e cujo talento lhe será de uma utilidade muito real, sem jamais poder impedi-lo do gozo de seus direitos. (CONDORCET, 1994a, p. 62. Tradução do autor).
}

A aprendizagem da Aritmética é uma exigência da cidadania. Ela é apontada, ao lado da leitura e da escrita e das primeiras noções de moral e de economia (relativa à agricultura ou à arte e ao comércio dependendo das exigências locais), como constitutiva da escola primária, onde se deveria aprender a ser livre. A "didática" do saber elementar proposta por Condorcet tem por meta não apenas ensinar fórmulas (algoritmos), mas levar também o aluno a aprender a raciocinar (filosofar) sobre a gênese de suas operações e 


\section{DOI: http://dx.doi.org/10.7867/1809-0354.2017v12n2p263-285}

mecanismos. Mostra-se como ensinar as crianças fazendo-as sentir os motivos de tudo o que aprendido, para que nada fique dado como arbitrário. Reafirmase que isso é fundamental em toda instrução, especialmente no caso da aritmética e da geometria. Condorcet destaca que não está em jogo apenas ensinar a calcular com segurança e facilidade, mas de desenvolver a faculdade de analisar ideias, raciocinar rigorosamente. Trata-se de aprender raciocinando.

Para Gomes (2002, p. 7), Condorcet "acredita na potencialidade da educação aritmética de desenvolver as faculdades intelectuais dos alunos, desde que seja realizada com ênfase na compreensão". A autora evidencia na referida obra de Condorcet uma proposta de "aprender compreendendo" em oposição ao "aprender fazendo", tal como esta pedagogia já se apresentava em livros didáticos já no início da modernidade (Veneza no século XV. Aritmética de Treviso) (GOMES, 2002). Ainda como lembra Gomes (2002, p. 3), são destacáveis os seguintes aspectos da didática de Condorcet: evitar passar "instruções diretas de como proceder para efetuar a operação, sem a preocupação de elucidar a razão dos procedimentos aí envolvidos"; dialogar com o leitor aprendiz "de maneira a convencê-lo da necessidade dos procedimentos mostrados"; não deixar de "examinar os motivos de cada um dos passos executados".

De qualquer modo, o ensino de aritmética é componente fundamental do saber elementar, do qual os elementos de lógica são inseparáveis. Estes apresentam de forma oculta no texto e devem ser explicitados ao longo das lições (GARAT, 1804, p. vi). Destaca-se, no manual de Condorcet, uma preocupação com o ensino de "fórmulas" para se calcular (algoritmos), sem que estes artifícios sejam aprendidos de modo mecânico, isto é, sem o uso da razão, da análise dos motivos. Como é destacado no Avertissement da primeira edição do texto (GARAT, 1804), visa-se não deixar as forças naturais (razão/capacidade de análise) sem exercícios, para não correr o risco de perder suas potências. "Assim as perdas podem ser maior do que os ganhos" (GARAT, 1804, p. vii. Tradução do autor). Trata-se de usar as fórmulas de modo que o aluno aprenda também a compreender os motivos e razões de todos os passos que foram dados para resolver as questões trabalhadas, o que 
permite ao aluno descobrir os segredos dos artifícios e as necessidades de cada passo dado. Garat (1804) destaca ainda que, na didática de Condocet, o intelecto e a mãos atuam juntos de modo que embora destoem um do outro, porque cada um tem seu tempo próprio, não se distanciam nas operações realizadas. Aprende, dessa forma, a lógica inerente ao cálculo fazendo a análise dos motivos que fundam suas regras, tal como fica indicado no livro para os professores, que acompanha o manual dos alunos.

Cabe destacar no texto Meios de aprender a contar seguramente e com facilidade como o modo de usar as técnicas/fórmulas proporciona o desenvolvimento da autonomia intelectual e moral, pois isso é acompanhado de uma análise filosófica/lógica e da exposição dos motivos para as passagens efetuadas. As "fórmulas" apresentam-se como máquinas intelectuais, "dispositivos capazes de aumentar e afiar as faculdades humanas" (GARAT, 1804, p. vi).

O texto didático de Condorcet objetiva desenvolver o aluno como sujeito de razão, garantindo também o desabrochamento da sua autonomia. A própria estrutura dialógica da obra, o modo de abordar o aprendiz nas lições, pretende garantir isso. Nota-se que o importante não é dar de imediato o conceito do que se está ensinando, mas trabalhá-lo analiticamente, partindo dos seus elementos e de suas relações. O autor sempre se direciona ao aluno, mostrando hipóteses, destacando cada passo dado, os motivos e as necessidades de tudo que se faz, simulando situações de aprendizagem e mesmo de erro, possibilitando um pensar junto a respeito de tudo o que se faz.

A formação da autonomia refere-se ao modo como a arbitrariedade metodológica é evitada. A este respeito conta o autor:

\footnotetext{
Ouvi um grande filósofo censurar a álgebra por querer conduzi-lo à verdade de uma maneira despótica, sem lhe dizer porque se lhe fazia seguir tal ou qual caminho, e como se chegava a saber que ele levaria ao resultado desejado; ele confessava que esse defeito, não do método em si, mas dos livros, inspirava-lhe uma espécie de desgosto involuntário por esse estudo. (CONDORCET, 1854, p. 38. Tradução do autor).
}

A lógica, tal como já havia apresentado Condillac (1798), é associada ao ensino dos cálculos como uma forma de mostrar a racionalidade e a não 
arbitrariedade dos mesmos. Assim apela-se para a evidência, mostrando a identidade entre proposições, o que justifica passagens de um conhecimento a outro. Por exemplo: $1+1=2 ; 8+1+1=10 ; 8+2=10$ (1854, p.4). Cabe mostrar ao aluno que o cálculo e o silogismo são processos semelhantes enquanto técnicas de raciocínios. Contudo deve se cuidar ao transformar cálculos em silogismos, nem sempre isso é o mais adequado, sobretudo devido à fadiga causada por essa atividade (CONDORCET, 1854, p. 118).

Define-se o raciocínio como a "operação pela qual se adere a uma proposição percebendo que ela resulta de outras já adotadas”, destacando que o raciocínio é um conjunto de proposições e seu resultado (CONDORCET,1854, p. 86. Tradução do autor). Mostra-se também como o raciocínio depende de juízos e da formação de ideias que os constitui. A análise é exercitada no processo de decomposição dos números "considerando separadamente as suas partes correspondentes" (CONDORCET, p. 119. Tradução do autor) $\mathrm{O}$ método analítico, afirma-se, é utilizado quando não se pode perceber imediatamente a identidade entre duas ideias. A identidade é descoberta com a comparação das partes análogas das ideias decompostas (CONDORCET, p. 119). A análise foi o método privilegiado por Condorcet não apenas para se chegar aos elementos, mas também para ensiná-los. Para ele, a análise permite o conhecimento da verdade de modo não arbitrário. Eis o método que deve perpassar toda a instrução e mesmo ser incorporado na prática de vida dos alunos.

\section{CONSIDERAÇÕES FINAIS}

A elementarização do saber em Condorcet obedeceu ao imperativo revolucionário, tal como ele entendia a palavra "revolução", isto é, como medidas e ações que produzem liberdade. Trata-se de um autor comprometido com o ideário liberal que buscou adequar a instrução pública à lógica do mercado, tal como este foi compreendido pelos Fisiocratas e A. Smith. A liberdade não foi vista como incompatível com a concentração da propriedade, a desigualdade de riqueza e a meritocracia. Nesse sentido, o saber elementar apresenta-se como uma forma de se orientar em um mundo com tais 


\section{DOI: http://dx.doi.org/10.7867/1809-0354.2017v12n2p263-285}

características, de modo a evitar a dependência do cidadão frente aos demais e ao Estado no que se refere a sua subsistência. $O$ ir além da instrução pública elementar ficou condicionado a lógica da desigualdade de "talentos" e de tempo para se dedicar aos estudos, o que restringia as pretensões dos filhos de trabalhadores pobres que também tinham que trabalhar, embora a estes fosse aberta a possibilidade de uma carreira de estudos com recursos públicos, quando provassem seus méritos.

É destacável, no entanto, a forma como Condorcet propôs o controle público da escola elementar para evitar que ela perdesse mesmo sua força emancipadora, especialmente apresentando garantias epistemológicas, jurídicas e didáticas capazes de submetê-la às exigências da razão. Contudo, trata-se de uma razão comum que não poderia ser monopolizada por ninguém, nem pelos sábios, nem pelos indivíduos, nem pela coletividade, nem pelos representantes e nem dos representados. Por isso, para o autor, a formação da razão comum não se desvincula do engendramento da moral do "povo" como forma de "instituição" da cidadania.

A matemática, ao mesmo tempo em que tende a produzir conhecimentos acessíveis apenas aos especialistas, é capaz também garantir a liberdade e a soberania do povo, quando este aprende a reconhecer nela uma autoridade racional. Mas ela precisa ser aprendida, até certo ponto, por meio da instrução pública, pois a sua elementarização é base para formar o "alfabeto" da razão comum. Nesse sentido, a alfabetização política significa aprender a analisar, calcular e a raciocinar num patamar capaz de tornar o cidadão em alguém que partilha a razão. A matemática aparece então como um escudo da razão coletiva contra a vontade entusiasmada da maioria e dos riscos de seu desvio da verdade.

Assim a elementarização escolar da matemática é uma exigência republicana tanto em seu conteúdo quanto em sua forma. A democracia condorcetiana depende do sucesso do ensino de matemática na instrução, caso contrário o indivíduo continuaria "cego" (a análise é como uma bengala para o cego) (CASSIRER, 1992), subordinado a uma autoridade estranha, cujo linguajar ele não compreende, limitando apenas a crer sem conhecer os motivos. 
Embora o saber elementar apresente-se como o início do percurso na cadeia do conhecimento cada vez mais elevado, a elementarização não deixaria de ser uma forma de justificar a desigualdade de extremos no acesso ao conhecimento, o que estaria de acordo com a aceitação de semelhante desigualdade na posse da propriedade e da riqueza. Seu efeito mais "positivo" seria o de tornar o cidadão funcional num mundo racionalizado, mas insensível às patologias de uma igualdade aparentemente de fato que a instrução pública e outras instituições criadas pela arte social garantiriam. As limitações da proposta de instrução pública de Condorcet são limitações do próprio ideário liberal por ele acatado e burilado. Mas seu pensamento é complexo o bastante para intimidar qualquer conclusão definitiva.

\section{SIDNEY REINALDO SILVA}

Doutor em Filosofia pela Universidade Estadual de Campinas. Pós-doutorado em Educação pela Universidade Estadual de Campinas. Atualmente é Professor de Filosofia do Instituto Federal do Paraná - Campus Paranaguá.

\section{REFERÊNCIAS}

BRU, B. Condorcet, mathématique sociale et vétité. Mathématique et Sciences humaines. Tomo 128, 1994, p. 5-14.

CASSIRER, E. A filosofia do lluminismo. Campinas: Unicamp, 1992.

CONDILLAC, É. B. d. La logique, ou Les premiers développements de l'art de penser. Paris: L'esprit Librarie, 1780.

CONDILLAC, É. B. d. Oeuvres de Condillac: La langue des calculs. Tome XXIII. Paris: Imprimerie de HOUEL, 1798.

CONDORCET, M. d. Moyens d'apprendre à compter sûrement et avec facilité. Paris: Mallet-Bachelier. 1854.

CONDORCET, M. d. (Marie Jean Antoine Nicolas de Caritat). Oeuvres, (ed. A Condorcet O'Connor et M F Arago, 1847) Reimpressão: Stuttgard-bad Cannstatt: Friedrich Frommann Verlag (Günther Holzboog), 1968.

CONDORCET, M. d. Esquisse d'un tableau historiques des progress de l'esprit humain. Fragment sur l'Atlantide. Paris: GG-Flammarion, 1988.

CONDORCET, M. d. Cinq mémoires sur l'instruction publique, Paris: GFFlammarion, 1994a. 
CONDORCET, M. d. Rapport et Projet de décret sur l'Instrutuction Publique, Présentées à l'Assemblée Nationalle, au non du Comité d'Instruction Publique. In: La Leçon de Condorcet. Une conception oublié de l'instruction pour tous nécessaire à une republique. Direction de J.DUMAZEDIER. Paris: L'Harmattan, 1994b

COUTEL, C.; KINTZLER, K. Presentation et Notes, in: CONDORCET, M. d. Cinq mémoires sur l'instruction públique. Paris: GF-Flamarion, 1994, pp 7-56.

COUTEL, C. Savoir scolaire et élémentarité chez Condorcet. SPIRALE - Revue de Recherches en Éducation - 1995, n 15 (7-30).

COUTEL, C. Pour l'instruction publique : Romme et Condorcet. In: Annales historiques de la Révolution française. №304, 1996a. pp. 327-344. Disponível em: http://www.persee.fr/issue/ahrf 0003-4436 1996 num 304 1. Acessado em 25/08/2017.

COUTEL, C. Décembre 1792: les objections au Rapport sur l'instruction publique. Réponses de Condorcet. In: Colloque Internacional. Condorcet: mathématicien, économiste, philosophe et homme politique. Paris: Minerve, 1996b.

COUTEL, C. Politique de Condorcet. Paris: Payot, 1996c.

COUTEL, C. A. L'école de Condorcet, contre l'orléanisme des esprits. Paris: Ellipses, 1998.

COUTEL, C. Condorcet: instituer le citoyen. Collection Bien Commun Paris: Michalon, 1999.

EPSTEIN, I. O paradoxo de Condorcet e a crise da democracia representativa. Estudos Avançados, 11 (30), 1997.

ESTLUND, D, WALDROW, J, GROFMAN, B, FELD, S. Democratic Theory and Public Interest: Condorcet and Rousseau Revisied. The American Political Science Rewiew, Volume 83, Issue 4, 1988, 1317-1340.

GARAT, D. J. Advertissement. In: Moyens d'apprendre à compter sûrement et avec facilité. Paris: Mallet-Bachelier, 1854. [1804]

GOMES, M. L. M. Quatro visões iluministas sobre a educação matemática: Diderot, D'Alembert, Condillac e Condorcet. Tese. Faculdade de Educação. UNICAMP, 2003.

GOMES, M. L. M. Um livro didático da França iluminista: a Aritmética de Condorcet. Zetetiké: Revista de Educação Matemática, v. 9, n. 15-16, 2009.

GOMES, M. L. M. Dois tempos e modos de ensinar a Aritmética. Revista História \& Educação Matemática, Rio Claro: Sociedade Brasileira de História da Matemática, v. 2, n. 2, p. 173-186, 2002. 
GROFMAN, B., FELD, S. Rousseau's General Will: A Condorcetian Perspective. The American Political Science Review. Vol. 82, No. 2 (Jun., 1988), pp. 567-576

KINTZLER, K., C. Condorcet, l'instruction publique et la naissance du citoyen. Paris: Folio - Essais, Minerve, 1994.

KINTZLER, K., C. L'instruction publique et la question de la cité chez Condorcet. Blog Mezetulle http://www.mezetulle.net/ (2013).

TROUVÉ, A. Elementaire: une notion désueté? Examen de ses principaux enjeux. Actes du Congrès Internacional Actualité de la Recherce en Éducation et en Formation (AREF), Strasbourg, 2007.

TROUVÉ, A. La notion de savoir élémentaire à l'école. Paris: L'Harmattanm, 2008.

TROUVÉ, A. Penser l'élémentaire. La fin du savoir élémentaire à l'école? Paris: I'Harmattan, 2010a.

TROUVÉ, A. Condorcet, Pestalozzi et la quête de la simplicité élémentaire. Actes du congrès de l'Actualité de la Recherche en Éducation et en Formation (AREF), Université de Genève, 2010b.

VALENTE, W. R. Tempos de Império: a trajetória da geometria como um saber escolar para o curso primário. Rev. bras. hist. educ., Campinas-SP, v. 12, n. 3 (30), p. 73-94, set./dez. 2012

VALENTE, W. R. Elementar. Cadernos de Trabalho. Coleção Cadernos de Trabalho, volume 1. São Paulo: Editora Livraria da Física, 2015.

WILLIAMS, D. Condorcet and Modernity. Cambridge: Cambridge University Press, 2007. 